\title{
Detection of Intranasally Delivered Bone Marrow-Derived Mesenchymal Stromal Cells in the Lesioned Mouse Brain: A Cautionary Report
}

\author{
Elena H. Chartoff,, ${ }^{1}$ Diane Damez-Werno, ${ }^{1}$ Kai C. Sonntag, ${ }^{1}$ \\ Linda Hassinger, ${ }^{1}$ Daniel E. Kaufmann, ${ }^{2}$ Jesse Peterson, ${ }^{1}$ Donna McPhie, ${ }^{1}$ \\ Anne M. Cataldo, ${ }^{1}$ and Bruce M. Cohen ${ }^{1}$ \\ ${ }^{1}$ Department of Psychiatry, McLean Hospital, Harvard Medical School, 115 Mill Street, Belmont, MA 02478, USA \\ ${ }^{2}$ Ragon Institute of Massachusetts General Hospital, Massachusetts Institute of Technology, and Harvard, Charlestown, \\ MA 02129, USA \\ Correspondence should be addressed to Elena H. Chartoff, echartoff@mclean.harvard.edu
}

Received 1 April 2011; Accepted 23 August 2011

Academic Editor: Hannele T. Ruohola-Baker

Copyright ( $\odot 2011$ Elena H. Chartoff et al. This is an open access article distributed under the Creative Commons Attribution License, which permits unrestricted use, distribution, and reproduction in any medium, provided the original work is properly cited.

\begin{abstract}
Bone marrow-derived mesenchymal stromal cells (MSCs) hold promise for autologous treatment of neuropathologies. Intranasal delivery is relatively noninvasive and has recently been reported to result in transport of MSCs to the brain. However, the ability of MSCs to migrate from nasal passages to sites of neuropathology and ultimately survive has not been fully examined. In this paper, we harvested MSCs from transgenic mice expressing enhanced green fluorescent protein (cells hereafter referred to as MSC-EGFP) and delivered them intranasally to wild-type mice sustaining mechanical lesions in the striatum. Using fluorescent, colorimetric, and ultrastructural detection methods, GFP-expressing cells were undetectable in the brain from 3 hours to 2 months after MSC delivery. However, bright autofluorescence that strongly resembled emission from GFP was observed in the olfactory bulb and striatum of lesioned control and MSC-EGFP-treated mice. In a control experiment, we directly implanted MSC-EGFPs into the mouse striatum and detected robust GFP expression 1 and 7 days after implantation. These findings suggest that - under our conditions-intranasally delivered MSC-EGFPs do not survive or migrate in the brain. Furthermore, our observations highlight the necessity of including appropriate controls when working with GFP as a cellular marker.
\end{abstract}

\section{Introduction}

Bone marrow-derived mesenchymal stromal cells (MSCs) are self-renewing precursors that-under some circumstances-have been shown to differentiate into cells of mesenchymal lineages such as bone, cartilage, muscle, and fat $[1,2]$. In addition, it has been reported both in vitro and in vivo that MSCs can be precursors of cells in neural lineages [3-6], although there is continuing controversy over these findings $[7,8]$. A number of studies have demonstrated that MSCs can engraft and survive for limited periods after direct implantation into the striatum [9-11]. However, controversy remains as to whether MSCs given in vivo have the intrinsic capacity to differentiate into neural cells, migrate within the brain, and survive for extended periods $[12,13]$. Regardless, MSCs are widely considered a potential source for the autologous treatment of a range of neurodegenerative or neurological disorders via delivery of growth factors or by replacement of damaged cells [14-16].

Invasive or inefficient routes are typically used to administer MSCs (i.e., intracerebroventricular, intracerebral, intraperitoneal, or intravascular), which would complicate clinical use. Intranasal administration is an attractive option for delivering MSCs to the brain because it is relatively noninvasive, and the olfactory region is a unique interface between the external environment and the central nervous system that bypasses the blood-brain barrier [17, 18]. Intranasal administration of small peptides, drugs, and viruses results in passage of these substances to the brain [18-23], although larger 
viral particles do not appear to migrate further than the olfactory bulb $[22,23]$. Although the efficiency of the intranasal route may be low, the potential advantages over more invasive techniques warrant further study.

Recently, it has been reported that intranasal delivery of fluorescently labeled MSCs to mice resulted in migration of some cells to the brain $[24,25]$ and attenuation of 6-OHDAmediated motor impairments in a model of Parkinson's disease [26]. The current study was designed to replicate the above findings and to test the hypothesis that intranasal delivery of MSCs to mice that sustained a striatal lesion would result in migration and engraftment of cells from the olfactory epithelium to the lesion site.

One issue that has hampered efforts to study the therapeutic potential of MSCs within the brain is the limited ability to track MSCs and differentiate them from endogenous cells. We used MSCs isolated from transgenic mice expressing EGFP under control of the CAG promoter, as has been described previously $[3,27]$. Because the presence of endogenous tissue autofluorescence can make it difficult to accurately detect relatively rare events of stem cell migration and survival in the brain, the inclusion of appropriate controls has been strongly recommended $[28,29]$, and we put special emphasis on discriminating between nonspecific and GFP-specific signals in brain tissue. Finally, we performed a control experiment in which we implanted MSCs directly into the striatum to verify that MSCs isolated and cultured under our conditions could survive in brain, as previously described [9-11].

\section{Materials and Methods}

2.1. Generation of an EGFP-Expressing Mesenchymal Stromal Cell (MSC) Line. For the generation of an EGFP-expressing MSC line (MSC-EGFP) bone marrow cells (BMC) were harvested from the femurs of 7 -week-old male transgenic mice $(N=6$ mice) expressing enhanced GFP (C57BL/6-Tg(CAGEGFP)1Osb/J; The Jackson Laboratories, Bar Harbor, MN) according to published protocols $[6,27,30]$ using Dulbecco's Modified Eagle Medium/High Glucose (DMEM/HG media; Invitrogen) supplemented with $2 \mathrm{mM}$ L-glutamine, and 15\% fetal bovine serum (FBS). To separate MSCs from the total BMC population, media was changed at $3 \mathrm{hr}$ and then every $8 \mathrm{hr}$ up to $72 \mathrm{hr}$ after initial plating of BMC suspension. At each media change, nonadherent cells were removed, leaving adherent MSCs [30]. Following isolation of MSCs, a clonal cell population was derived as previously described [6], except that the cells were propagated for 3 weeks in DMEM/low glucose (DMEM/LG; Sigma) with 2\% FBS (Hyclone), $1 \mathrm{nM}$ dexamethasone (Sigma), $2.5 \mathrm{ng} / \mathrm{mL}$ bFGF, $10 \mathrm{ng} / \mathrm{mL} \mathrm{mEGF}$, and $10 \mathrm{ng} / \mathrm{mL} \mathrm{mLIF}$ (as in [27]).

2.2. Flow Cytometry (FCM). Cultured BMCs and MSCEGFPs were trypsinized, washed in PBS, and subjected to standard FCM analysis using the Mouse Multipotent Mesenchymal Stromal Cell Marker Antibody Panel (R\&D Systems; catalog \#SC018) according to the conditions provided by the manufacturer with 568-labeled Alexa Fluor secondary antibodies (Invitrogen) and an LSR Fortessa FACS machine
TABLE 1: Treatment groups.

\begin{tabular}{lcccccc}
\hline \multicolumn{7}{c}{ Numbered mice/group } \\
Pretreatment & MSC & Delivery route & $3 \mathrm{hr}$ & $1 \mathrm{~d}$ & $7 \mathrm{~d}$ & $2 \mathrm{mos}$ \\
\hline Mechanical & Veh & IN & 3 & 3 & 3 & 3 \\
lesion & MSC-EGFP & IN & 3 & 3 & 2 & 2 \\
\multirow{3}{*}{ No lesion } & Veh & IN & 2 & & & \\
& MSC-EGFP & IN & 2 & & & \\
& Veh & IS & & 3 & 3 & \\
& MSC-EGFP & IS & & 3 & 3 & \\
\hline
\end{tabular}

Total mice: 38 .

Abbreviations: IN: intranasal; IS: intrastriatal.

(BD Biosciences). Data were analyzed using FlowJo software version 8.7.3 (TreeStar).

2.3. Mice. A total of $38 \mathrm{C} 57 \mathrm{Bl} / 6 \mathrm{~J}$ mice (Jackson Laboratories, Bar Harbor, ME) were used in this study. Mice weighed 25$27 \mathrm{~g}$ at the time of the study (approximately 10-12 weeks old) and were maintained on a 12-h light/dark (7:00 AM to 7:00 PM) cycle with ad libitum access to food and water except during testing. Experiments were conducted in accordance with the 1996 National Institute of Health Guide of the Care and Use of Laboratory Animals and McLean Hospital policies. See Table 1 for a breakdown of the number of mice per treatment group.

2.4. Intranasal MSC-EGFP Delivery. A total of 26 mice were used for studies of intranasal MSC-EGFP delivery (see Table 1). A surgical (sham) lesion of the dorsal striatum was performed on mice $(N=22) 3$ weeks prior to intranasal delivery of MSC-EGFPs. This time frame was used because our long-term goal was to determine whether intranasal administration of MSCs can rescue neurochemical and behavioral deficits induced by 6-hydroxydopamine (6-OHDA) lesions of the dopaminergic system, which take approximately 3 weeks to occur [31]. In the current study, which did not involve 6-OHDA, mice were anesthetized with an intraperitoneal (IP) injection of a ketamine $\mathrm{HCl}(100 \mathrm{mg} / \mathrm{kg})$ and xylazine $\mathrm{HCl}(15 \mathrm{mg} / \mathrm{kg}$ ) mixture (Sigma). Mice were immobilized in a stereotaxic instrument and received 2 unilateral microinjections of $0.01 \%$ ascorbic acid $(N=22$ mice; 2 injections $\times 1.5 \mu \mathrm{L} /$ injection) into the left striatum. Ascorbic acid was used because it is a common vehicle for 6-OHDA. Injection coordinates were $1.0 \mathrm{~mm}$ anterior to Bregma, $1.4 \mathrm{~mm}$ lateral to midline, and $3.3 \mathrm{~mm}$ ventral to the skull surface; $0.1 \mathrm{~mm}$ anterior to Bregma, $1.6 \mathrm{~mm}$ lateral to midline, and $3.3 \mathrm{~mm}$ ventral to the skull surface [32]. Microinjections were done at a rate of $0.35 \mu \mathrm{L} / \mathrm{min}$ with a 33-gauge injector needle (Plastics One, Roanoke, VA) attached by polyethylene (PE) tubing to a $10 \mu \mathrm{L}$ Hamilton syringe in a syringe pump. Each 4.3-min infusion was followed by a 3-min wait period to allow for diffusion before removing the injector needle.

Three weeks after lesion, recipient mice received either intranasal vehicle or MSC-EGFPs. An additional 4, unlesioned, mice also received intranasal MSCs (see Table 1). Mice were lightly anesthetized with an IP injection of a ketamine 
$\mathrm{HCl}(50 \mathrm{mg} / \mathrm{kg})$ and xylazine $\mathrm{HCl}(7.5 \mathrm{mg} / \mathrm{kg})$ mixture (Sigma). Using a standard gel-loading pipette tip, $10 \mu \mathrm{L}$ of sterile phosphate buffered saline (PBS) or PBS containing 25,000 MSC-EGFPs was administered dropwise into each of the nares, resulting in delivery of 50,000 MSC-EGFPs per mouse. PBS was chosen as the vehicle based on previously published reports $[24,26]$. Mice were sacrificed $3 \mathrm{~h}, 1 \mathrm{~d}, 7 \mathrm{~d}$, or 2 months after MSC-EGFP delivery.

2.5. Intrastriatal MSC-EGFP Delivery. Mice $(N=12)$ were anesthetized with an intraperitoneal (ip.) injection of a ketamine $\mathrm{HCl}(100 \mathrm{mg} / \mathrm{kg})$ and xylazine $\mathrm{HCl}(15 \mathrm{mg} / \mathrm{kg})$ mixture (Sigma). Mice were immobilized in a stereotaxic instrument and received 1 unilateral microinjection $(2 \mu \mathrm{L}$ at $0.2 \mu \mathrm{L} / \mathrm{min})$ of 75,000 MSC-EGFPs in culture media (DMEM/F12 containing $0.66 \%$ glucose, $0.125 \% \mathrm{NaHCO}_{3}$, and $0.0056 \mathrm{M}$ HEPES with $0.05 \%$ DNAse) or media alone, as in Moloney et al. [11] using a 26-gauge Hamilton syringe. Injection coordinates were: $1.0 \mathrm{~mm}$ anterior to Bregma, $1.4 \mathrm{~mm}$ lateral to midline, and $3.3 \mathrm{~mm}$ ventral to the skull surface. Mice were sacrificed 1 or $7 \mathrm{~d}$ after MSC-EGFP delivery.

2.6. Immunohistochemistry. Mice were sacrificed at various timepoints after MSC-EGFP delivery by sodium pentobarbital overdose $(130 \mathrm{mg} / \mathrm{kg}, \mathrm{IP})$ and were transcardially perfused with $10 \%$ formalin in phosphate buffer (Fisher). Brains were kept in formalin at $4^{\circ} \mathrm{C}$ overnight and then saturated in $30 \%$ sucrose in phosphate buffered saline for 3 days until sectioning on a Vibratome tissue processor (Series 1000, TPI, St. Louis, MO). Sagittal or coronal sections $(30 \mu \mathrm{m})$ were cut through the entire brain and collected in $10 \%$ formalin. For fluorescent detection of MSC-EGFPs, tissue sections were either mounted directly to view endogenous GFP, or processed for immunohistochemistry.

Tissue sections were washed $3 \times 5 \mathrm{~min}$ in diluting buffer ( $2 \%$ bovine serum albumin, $0.9 \% \mathrm{NaCl}, 0.4 \%$ Tween 20 and $1 \%$ normal goat or horse serum in $0.1 \mathrm{M}$ phosphate buffered saline PBS) then blocked with 20\% normal goat or horse serum in $0.1 \mathrm{M}$ PBS for $30 \mathrm{~min}$. Primary antibodies were diluted in diluting buffer and sections were incubated overnight at room temperature. For fluorescence imaging, some sections were counterstained with $1 \mu \mathrm{g} / \mathrm{mL}$ DAPI ( $4^{\prime} 6-$ diamidino-2-phenylindole; Sigma). Primary antibodies used were GFP (polyclonal made in rabbit, $1: 2000$, Abcam) and glial fibrillary acidic protein (GFAP, polyclonal made in rabbit, $1: 250$, DAKO Corporation, Carpinteria, CA). Secondary antibodies included Alexa Fluor 488 fluorophore made in goat (anti-rabbit, 1:1000, Invitrogen, Carlsbad, CA) and biotinylated anti-rabbit IgG $(1: 1000)$ followed by streptavidin-conjugated Alexa 568 fluorophore ( $1: 200$, Invitrogen). In an attempt to quench autofluorescence, some tissue sections were pretreated with $0.3 \%$ Sudan Black in $0.1 \mathrm{M}$ PBS (Sigma) 5 min prior to immunohistochemistry [(see Supplementary Figure 2 in supplementary material which is available online at doi:10.4061.2011.586586)].

Tissue sections adjacent to those used for fluorescence were processed for nonfluorescent, colorimetric detection of GFP using an avidin-biotin system (Vectastain ABC kit;
Vector) with diaminobenzidine (DAB; Vector) as the chromagen. GFP polyclonal antibody (Abcam) made in rabbit was used at $1: 2000$ and biotinylated anti-rabbit IgG (Vector Laboratories, Burlingam, CA) was used at $1: 1000$.

Sections were visualized and captured with an upright Zeiss Z1 microscope connected to a digital camera (Zeiss AxioCam HRc). Images were processed using AxioVision software (Zeiss) and Photoshop (version 8.0; Adobe Systems Incorporated, San Jose, CA). Negative controls for immunohistochemical staining were performed by omitting the primary antibody. Also, brain regions contralateral to the lesion were examined and served as internal controls.

For ultrastructural analysis of MSC-EGFPs at the lesion sites, tissue sections processed for GFP IHC with DAB were post fixed with $1 \%$ osmium tetroxide $\left(\mathrm{OsO}_{4}\right)$ in sodium phosphate buffer, $\mathrm{pH}$ 7.2, dehydrated through graded ethanols, and flat embedded in Embed-812 between ACLAR sheets (EMS, Fort Washington PA). Appropriate regions of the tissue were attached to epon blanks and ultrathin sections were cut using a Reichert-Jung ultra-microtome, mounted on $\mathrm{Cu}$ grids and lightly stained with aqueous uranyl acetate (10 min) and Reynold's lead citrate (4 min). Sections were examined using a Jeol 1200EX transmission electron microscope (JEOL, Tokyo, Japan) with an AMT Digital Imaging System (Advanced Microscopy Techniques Corp., Danvers MA).

\section{Results}

3.1. Phenotypic Profile of MSC-EGFPs. Using FCM and the Mouse Multipotent Mesenchymal Stromal Cell Marker Antibody Panel, we phenotyped the MSC-EGFP line (passage 4) and compared it to normal C57BL/6 BMCs three weeks after harvest and growth in serum-containing mitogen-free conditions (3 passages; Figure 1(a)). The total population of BMCs segregated into two fractions: large cells, which weakly expressed Sca-1, but strongly expressed CD29 and CD44, and which were negative for CD106, CD105, CD73, CD11b, and CD45, and small cells, which exhibited no expression of any of the markers analyzed. The MSC-EGFPs were strongly positive for Sca-1, CD29, and CD44 (similar to the large fraction of BMCs) while negative for CD106, CD105, CD73, CD11b, and CD45.

3.2. Detection of EGFP in MSCs. MSCs were used at passage 4 and the presence of GFP was confirmed in the cultured cells prior to delivery to the animals (see Figures $1(\mathrm{~b})-1(\mathrm{~d})$ ). The MSC-EGFPs had a flattened appearance and a fibroblastlike shape (Figure 1(b)). These cells exhibited bright green fluorescence (Figure 1(c)) when visualized with a GFP bandpass filter, but did not fluoresce when visualized with a Texas Red bandpass filter (Figure 1(d)), confirming that the green fluorescence was due to GFP expression and not autofluorescence. Thus, immediately before intranasal administration, MSC-EGFPs were viable and expressed GFP.

3.3. Detection of MSC-EGFPs Delivered Intranasally. Sagittal or coronal brain sections from striatally lesioned mice treated intranasally with either saline or MSC-EGFP were examined for the presence of GFP-positive cells by fluorescence 

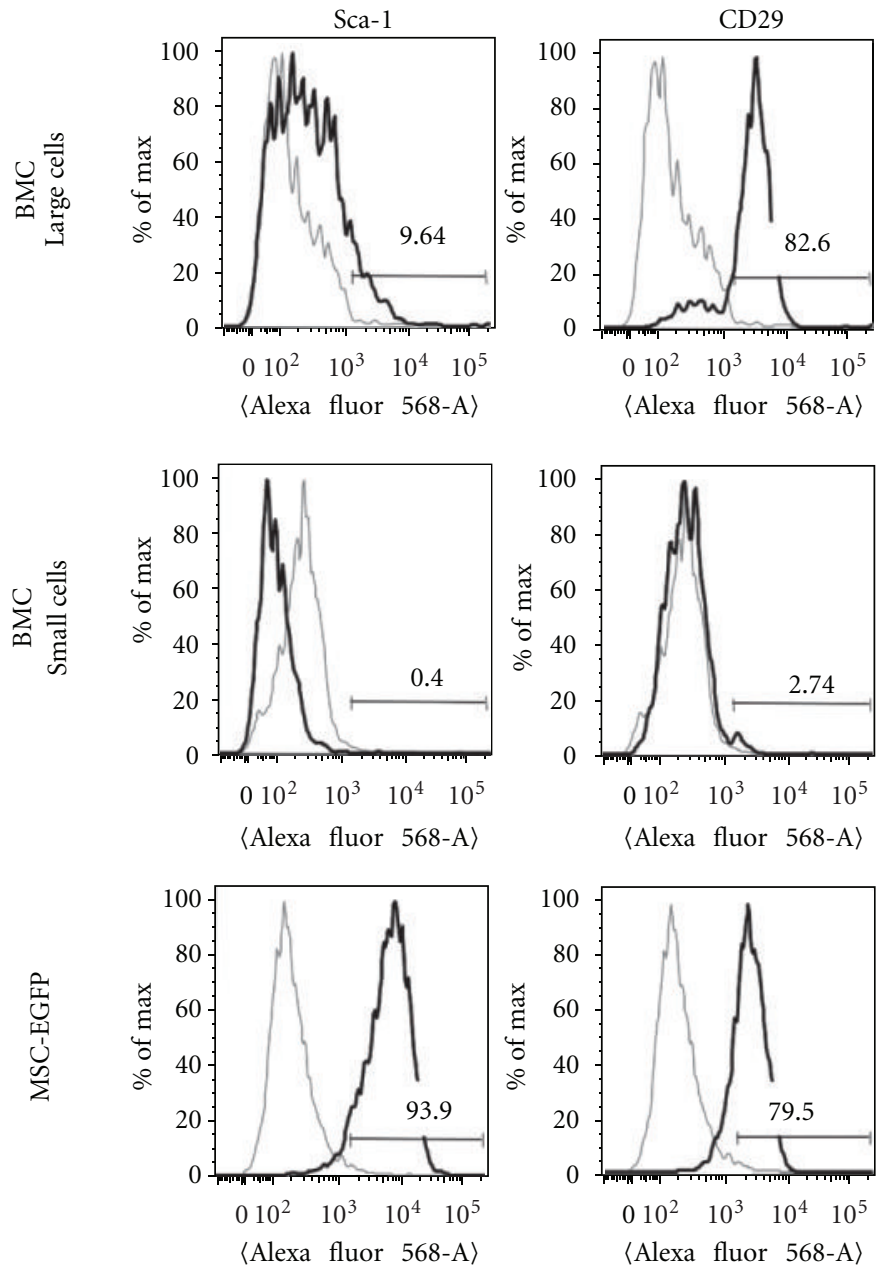

CD29
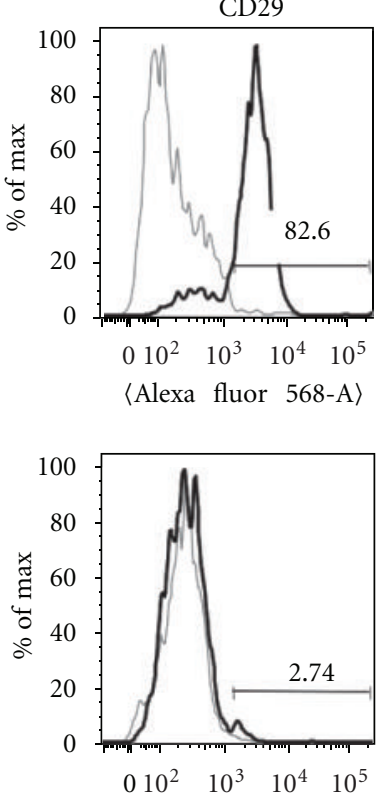

〈Alexa fluor 568-A
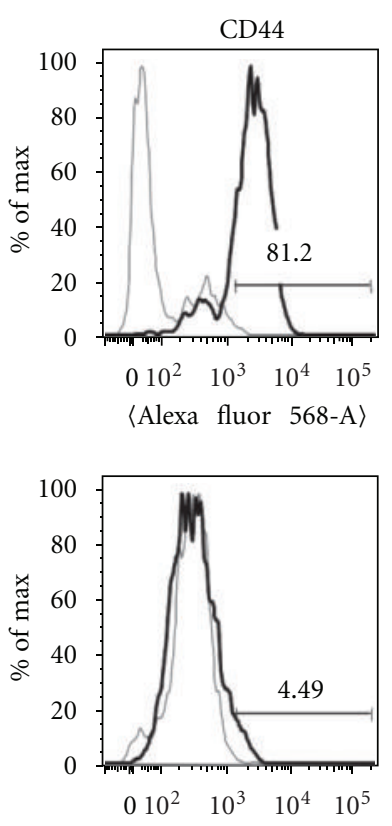

〈Alexa fluor 568-A)

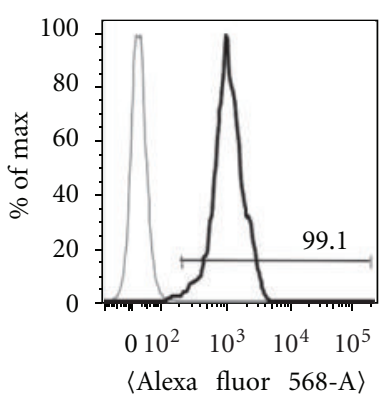

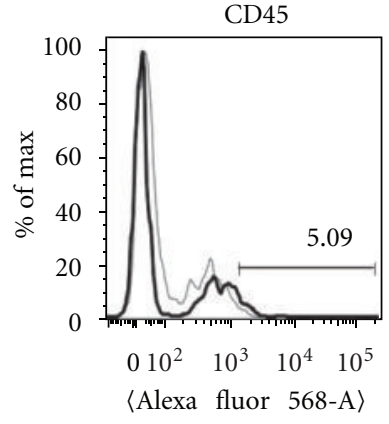
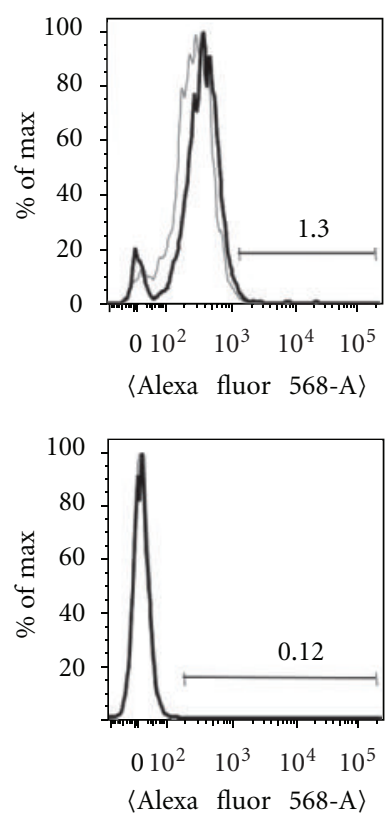

(a)

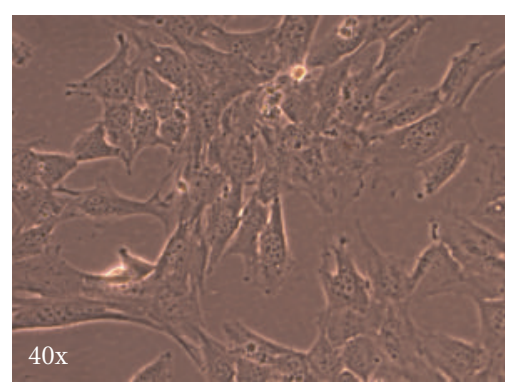

(b)

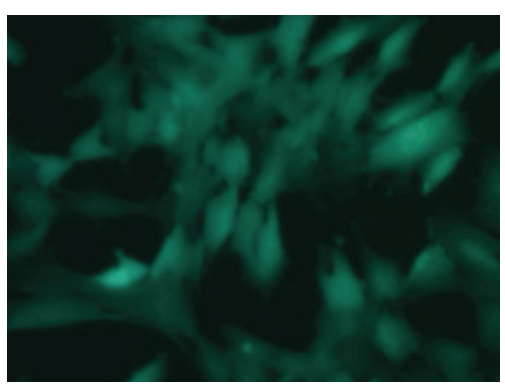

(c)

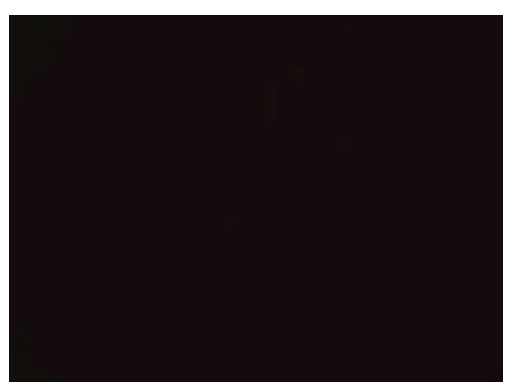

(d)

FIGURE 1: Phenotypic profiling of cultured BMCs and MSC-EGFPs. (a) BMCs cultured for three weeks in serum-containing mitogenfree conditions and mitogen-activated MSC-EGFPs at passage 18 were analyzed by Flow cytometry (FCM) using the Mouse Multipotent Mesenchymal Stromal Cell Marker Antibody Panel (R\&D Systems). Shown are the positively staining markers Sca-1, CD29, and CD44, and an example of negative staining for the hematopoietic marker CD45. ((b), (c), (d)) Undifferentiated mesenchymal stromal cells derived from adult EGFP transgenic mice (MSC-EGFP) appear as large, flat fibroblast-like cells that express high levels of the enhanced green fluorescent protein reporter, EGFP. MSC-EGFPs are shown under (b) phase contrast and (c) GFP bandpass filter, demonstrating eGFP expression and (d) Texas Red bandpass filter, demonstrating lack of autofluorescence.

microscopy. Three hours after MSC-EGFP delivery, fluorescent cell-like structures were visible within the glomerular layer of the OB, but they did not resemble the MSC-EGFPs seen in culture. This fluorescence in OB was detectable at similar intensity levels when viewed under multiple emission filters, suggesting autofluorescence. One possibility was that GFP expression was low in the $\mathrm{OB}$, so in an attempt to amplify GFP signal, we used an antibody to GFP for subsequent observations. Under these conditions, similar fluorescent cell-like structures were visible within the glomerular 


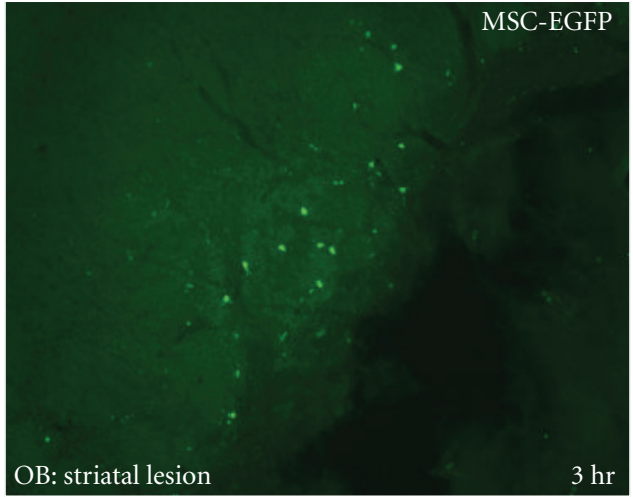

(a)

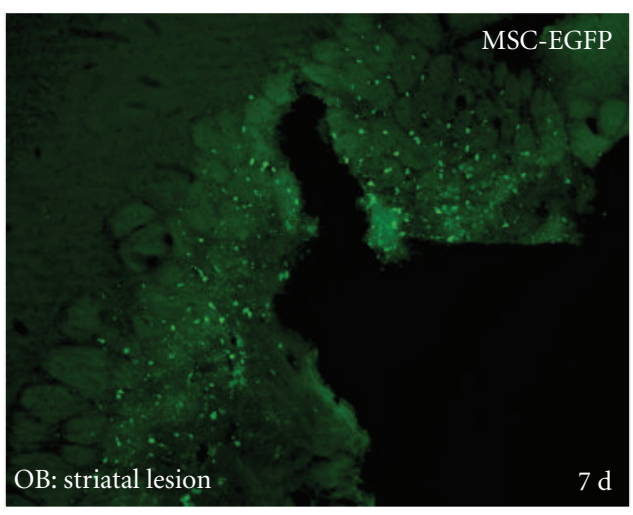

(b)

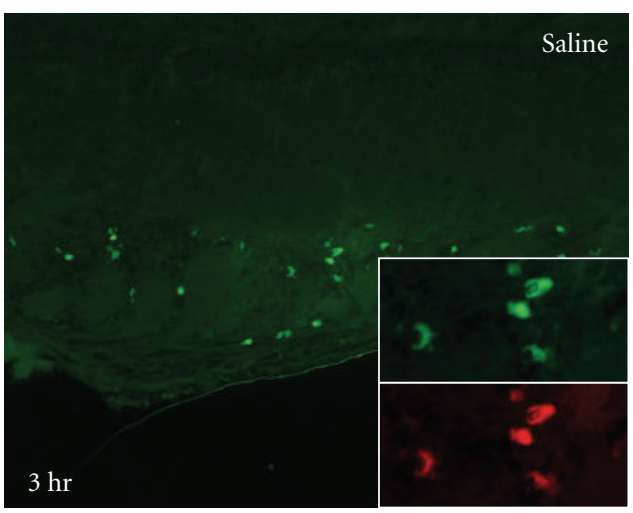

(c)
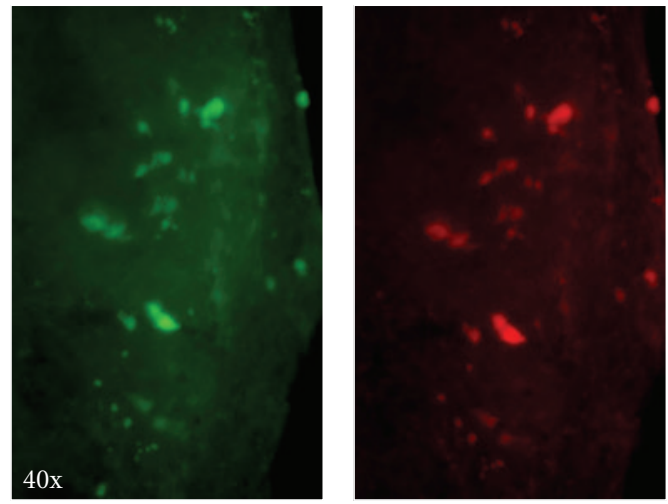

$\left(a^{\prime}\right)$
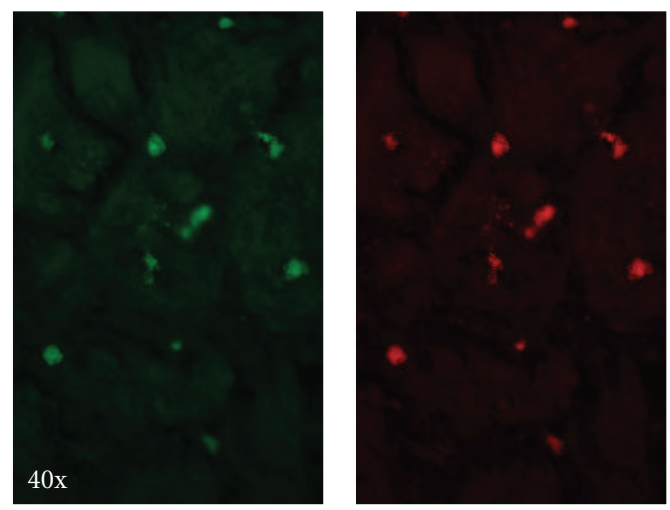

(b')

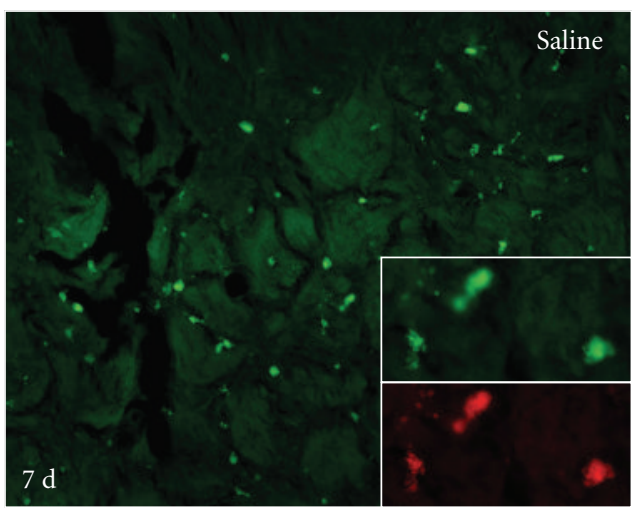

(d)

FIgURE 2: Autofluorescence in the olfactory bulb (OB) after intranasal delivery of MSC-EGFPs to mice with prior mechanical lesions in striatum. Fluorescent structures are observed within the glomerular layer of the $\mathrm{OB}$ at 3 hours and 7 days after intranasal administration of MSC-EGFPs (a), (b) or saline (c), (d). Higher magnification images of the OB at 3 hours $\left(\left(a^{\prime}, c\right)\right.$ inset) and 7 days $\left(\left(b^{\prime}\right.\right.$, d) inset) imaged with both the GFP and Texas Red bandpass filters show a one-to-one correlation between the number and intensity of stained structures.

and-to a lesser extent-the external plexiform layers of the $\mathrm{OB}$ at $3 \mathrm{hr}, 1$ and 7 days, and 2 months after MSC-EGFP delivery to mice with striatal lesions when viewed with a GFP bandpass filter (for $3 \mathrm{hr}$ and $7 \mathrm{~d}$, see Figures 2(a) and 2(b)). However, fluorescence of identical intensity and spatial distribution was observed with all filters, including a Texas Red bandpass filter (Figures $2\left(\mathrm{a}^{\prime}\right)$ and $2\left(\mathrm{~b}^{\prime}\right)$ ). Similar fluorescent structures were visible within the glomerular cell layer in striatally lesioned mice that received intranasal vehicle
(Figures 2(c) and 2(d)). No fluorescence above background was observed in deeper layers of the OB or along established routes of migration such as the olfactory-neuronal pathway [18].

Robust autofluorescence was also observed in the striatum along the trajectory of the injector needle used to make the mechanical striatal lesions. Regardless of intranasal treatment (MSC-EGFPs or saline), the autofluorescence looked similar. At day 7 after intranasal treatment, the fluorescence 


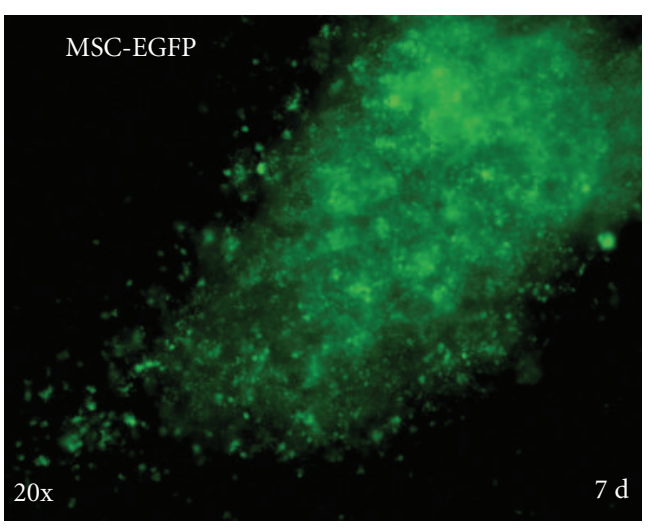

(a)

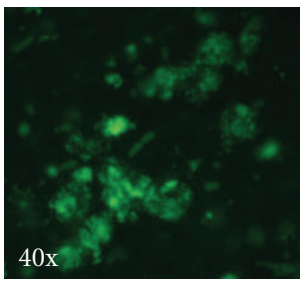

(c)

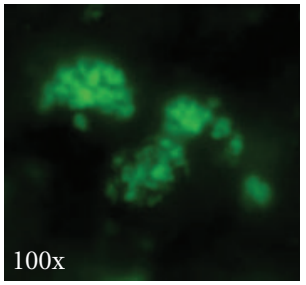

(e)

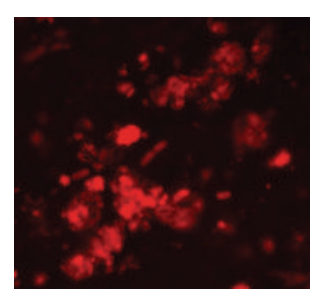

$\left(c^{\prime}\right)$

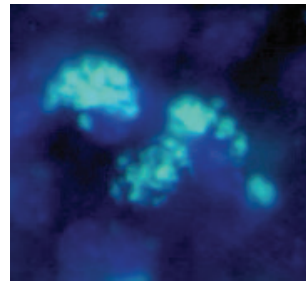

$\left(\mathrm{e}^{\prime}\right)$

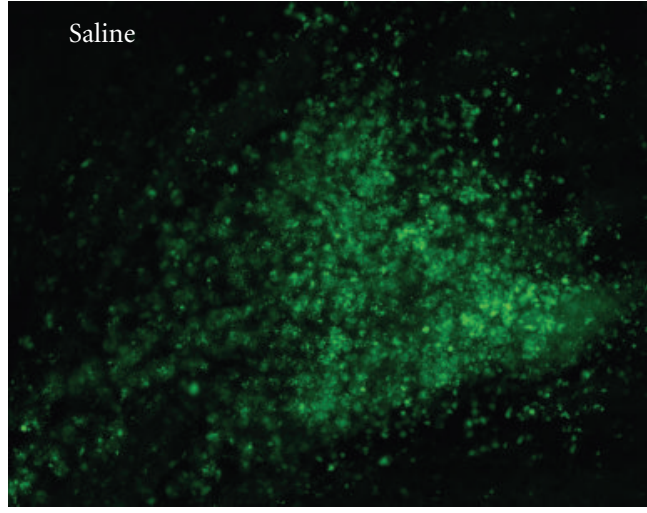

(b)

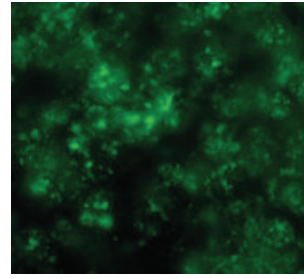

(d)

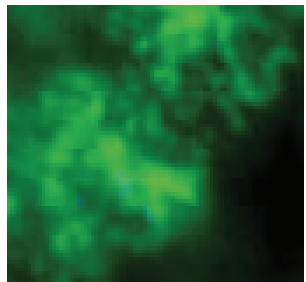

(f)

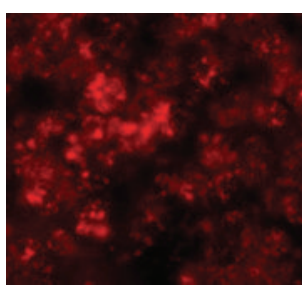

$\left(d^{\prime}\right)$

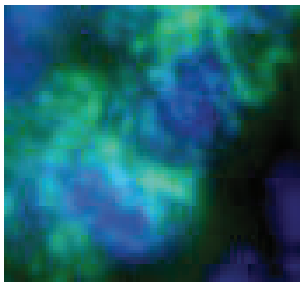

$\left(\mathrm{f}^{\prime}\right)$

FIGURE 3: Autofluorescence in the striatum of mice that received mechanical striatal lesions followed 3 weeks later by intranasal saline or MSC-EGFPs. Bright particulate fluorescence is observed at the termination of the lesion injector needle at 7 days after intranasal delivery of MSC-EGFPs (a, c, e) or saline (b, d, f). The number of structures and intensity of fluorescence is the same on the GFP and Texas Red bandpass filters $\left(c^{\prime}\right.$ and $\left.d^{\prime}\right)$.

had an "explosive," particulate appearance (Figures 3(a) and $3(\mathrm{~b}))$ that was of equal intensity under both red and green fluorescent filters (Figures $3(\mathrm{c})-3\left(\mathrm{~d}^{\prime}\right)$ ). At higher magnification, some of the fluorescent bodies appeared loosely associated with DAPI-stained nuclei, although they had a punctate appearance not seen in healthy tissue (Figures $\left.3(\mathrm{e})-3\left(\mathrm{f}^{\prime}\right)\right)$. At 2 months after intranasal treatment, the autofluorescence had dissipated significantly from around the needle track, but it was still indistinguishable between MSC-EGFP- and saline-treated mice (Supp. Figures $1(\mathrm{~A})$ and $1(\mathrm{~B})$ ), with similar intensities under the red and green filters (Supp. Figures 1(C) and 1(D)). Some of the fluorescent bodies appeared to be associated with DAPIstained nuclei (Supp. Figures 1(E) and 1(F)). Importantly, the fluorescent structures were difficult to define, and it was not possible to clearly focus on them, similar to what is described for lipofuscin autofluorescence [33].

Several methods exist to reduce (quench) autofluorescence in brain (see [33]). Sudan Black is an opaque dye that is effective at obscuring lipofuscin without interacting with it at the chemical level. It has been shown to reduce autofluorescence at concentrations that have minimal impact on immunohistochemical staining. We pretreated a subset of tissue sections with Sudan Black (0.3\%) and examined GFP and tyrosine hydroxylase (TH) staining in the striatum. Sudan Black pretreatment globally reduced fluorescence intensity, but did not eliminate autofluorescence at concentrations that still allowed for detection of TH (Supp. Figure 2).

To determine whether the autofluorescence observed in our tissue was associated with a glial response, we colabeled tissue from mice sacrificed 2 months after intranasal MSC administration with anti-GFP and anti-GFAP antibodies. Autofluorescent bodies in the side of the striatum ipsilateral to the lesion were surrounded by strong GFAP expression, which was localized along the injector needle trajectory (Figures 4(a) and 4(b)). In contrast, low, background levels of GFAP staining and autofluorescence were observed on the side of the striatum contralateral to the lesion (Figure 4(c)). 


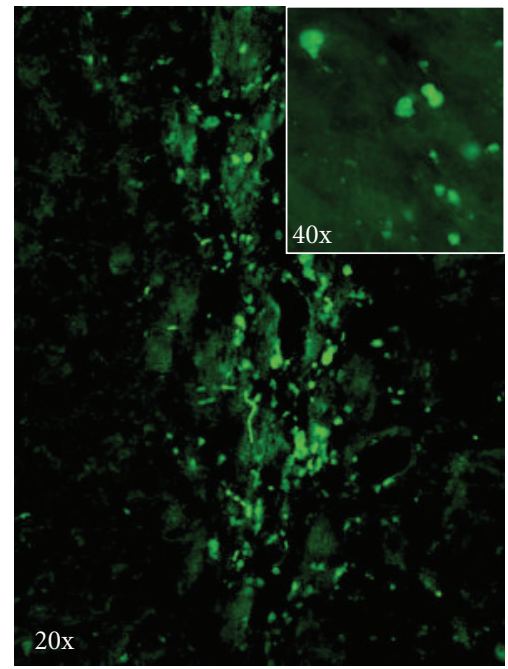

(a)

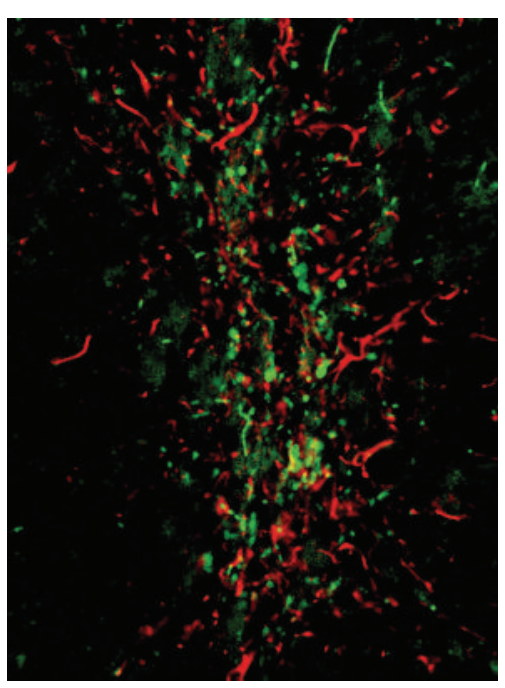

(b)

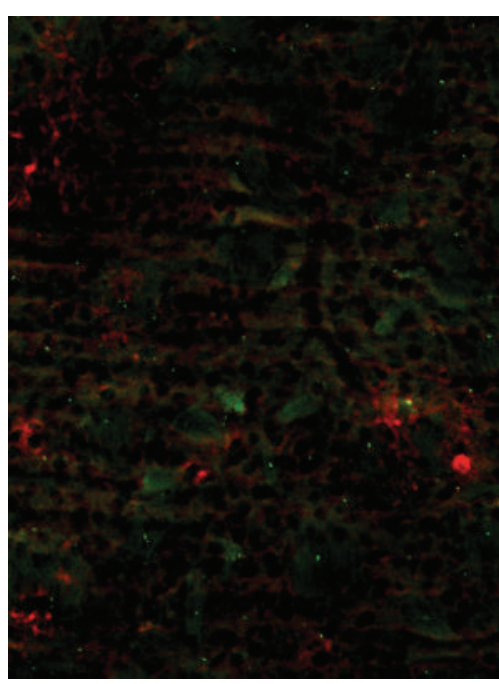

(c)

FIGURE 4: Double label immunohistochemistry shows close association between glial fibrillary acidic protein (GFAP) and autofluorescence along the injector needle track in the striatum, 2 months after intranasal delivery of MSC-EGFPs. (a) Green autofluorescence along needle track. Inset, higher-magnification image from (a). (b) GFAP (red) expression is strong along the needle track. (c) Substantially less GFAP, and no green autofluorescence, is detected in the contralateral striatal hemisphere.

\begin{abstract}
3.4. Detection of EGFP In Vivo: Light Microscopy. To circumvent the issue of autofluorescence seen in fluorescence microscopy, we performed additional immunohistochemistry on adjacent tissue sections from mice treated intranasally with MSC-EGFPs using the same GFP polyclonal primary antibody and a biotinylated secondary antibody that can be detected with an avidin-biotinylated peroxidase enzyme complex reaction. Tissue sections were counterstained with cresyl violet. In sections from mice treated with either intranasal saline or MSC-EGFPs, a dense, DAB-positive cluster was observed at the distal end of the injector needle tracks in the striatum (not shown). At higher magnification, this DAB-positive cluster appeared punctate and was not clearly associated with cresyl violet stained nuclei (Figure 5(a)). In addition, it was not possible to focus on these structures, which had an amorphous appearance.
\end{abstract}

\subsection{Ultrastructural Analysis of DAB-Positive Structures in the} Striatum. To determine whether GFP-specific staining, and by implication MSC-EGFPs, was present amid the nonspecific and amorphous structures observed in the striatum with both fluorescence and light microscopy, we performed electron microscopy on DAB-stained striatal tissue from mice that received intranasal MSC-EGFPs either 7 days or 2 months prior to sacrifice. We observed many cell-like structures that were darker than surrounding tissue and cells (Figures 5(b)-5(d)). A number of these cells appeared to be at advanced stages of degradation: cellular structures such as mitochondria, endoplasmic reticulum, and Golgi were not detectable, the cytoplasm was filled with inclusion bodies, lipofuscin, and lysozymes, and the nucleus, when observable, was relatively small and eccentric (Figure 5(c)). A different population of shrunken, electron dense structures with dark, pyknotic chromatin were also observed (Figure 5(d)). Based on this morphology, it is likely that these structures are necrotic cells [34]. Interestingly, in these smaller necrotic cells, organelles such as mitochondria, endoplasmic reticulum, and Golgi apparati could still be detected. For comparison, a healthy neuronal cell can also be seen in the lower right corner of Figure $5(b)\left(B^{\prime}\right)$, in which normal cellular structures are visible, the nucleus is intact and centrally located with diffuse and light chromatin, and there is no evidence of inclusion bodies.

3.6. Detection of MSC-EGFPs Delivered Intrastriatally. To verify that MSC-EGFPs cultured under our conditions were able to survive in brain, as in previous reports [9-11], we performed a control experiment in which MSC-EGFPs were implanted directly into the striatum of recipient mice. One day after intrastriatal injection, GFP-specific fluorescence was detected in the striatum in a cellular graft concentrated around the injection site (Figures 6(a), 6(b), and 6(c)). Visualization of the MSC-EGFP graft under a Texas Red bandpass filter showed no detectable fluorescence (Figure 6( $\left(^{\prime}\right)$ ). No MSC-EGFPs were detected outside of the graft area, suggesting a lack of migration at this time point. Seven days after intrastriatal injection, GFP-specific fluorescence was detected in the striatum in a cellular graft concentrated around the injection site similar to that observed at 1 day (Figures 6(e), 6(f), and 6(g)). In contrast, visualization of the MSC-EGFP graft under a Texas Red bandpass filter showed a diffuse, low level of fluorescence interspersed with bright puncta (Figure $\left.6\left(\mathrm{~g}^{\prime}\right)\right)$. This suggests the presence of autofluorescent inclusion bodies that may be associated with dying MSC-EGFPs. Olfactory bulb tissue was also examined at 1 and $7 \mathrm{~d}$ after intrastriatal implantation. Fluorescent cell-like structures were visible within the glomerular layer of the $\mathrm{OB}$ (Figures 6(d) and 6(h)). However, fluorescence of identical 


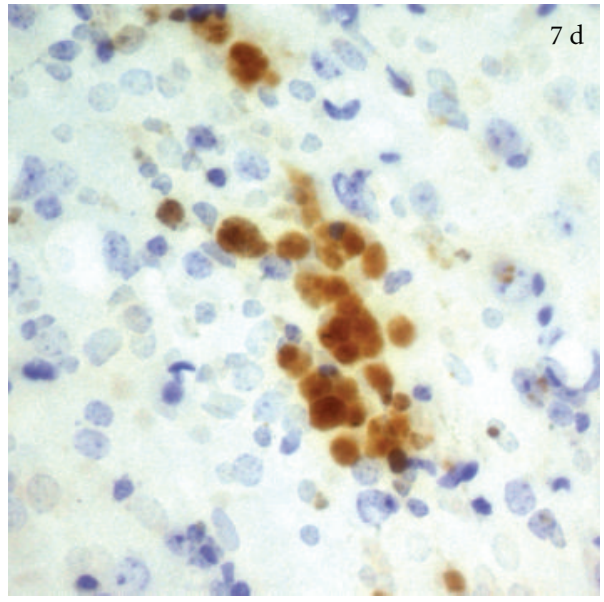

(a)

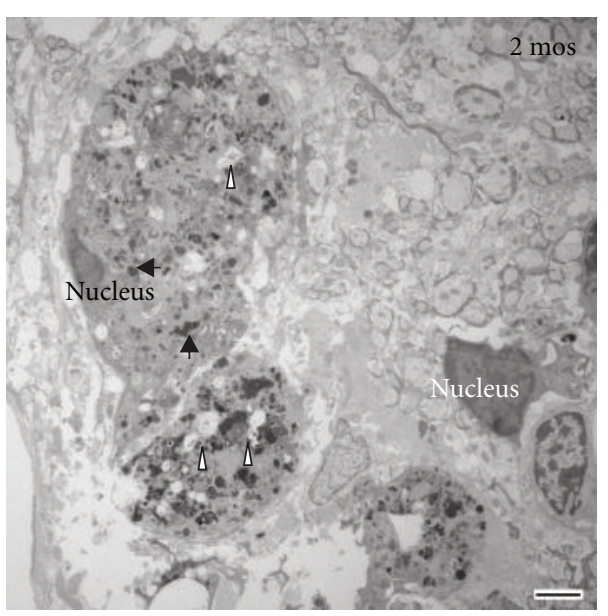

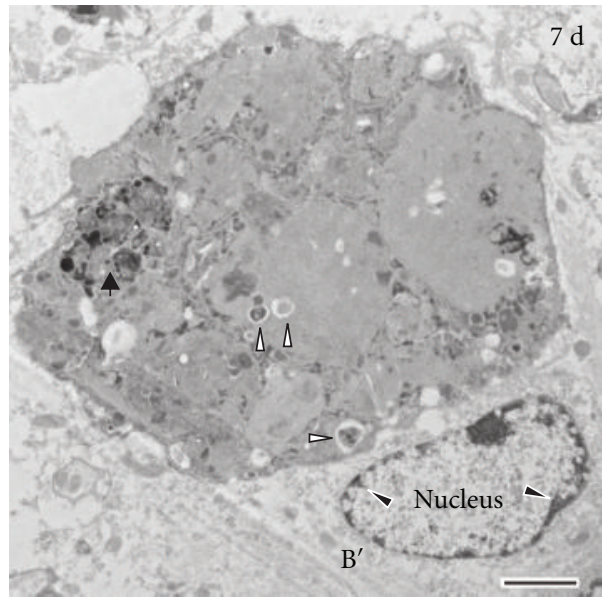

(b)

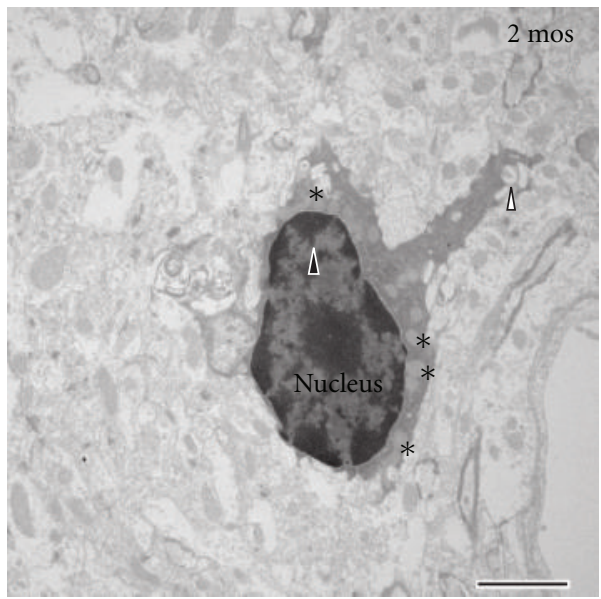

\Chromatin

* Mitochondria

(d)

FIGURE 5: Ultrastructural analysis of striatal tissue from mice intranasally administered MSC-EGFPs. (a) Representative example of light microscopy image of DAB-stained tissue in striatum. (b) Characteristic structure observed in striatum of mice at 7 days after MSCEGFP treatment. Darkened cell-like structures have few if any discernable organelles but are full of inclusion bodies, lipofuscin, and other degenerated products. A healthy nucleus and cell can be seen in the lower right portion of the panel (B'). 2 months after MSC-EGFP treatment, similar darkened structures were detected (c) as well as darkened cells with pyknotic nuclei, shrunken cytoplasm, and vacuoles (c) and (d). Scale bar is $2 \mu \mathrm{m}$.

intensity and spatial distribution was observed with all filters, including a Texas Red bandpass filter (Figures $6\left(\mathrm{~d}^{\prime}\right)$ and $\left.6\left(\mathrm{~h}^{\prime}\right)\right)$, suggesting the presence of endogenous autofluorescence in the OB. Thus there was no detectable migration of MSCs from the injection site following 7-day survival, but there was evidence of MSC loss at the injection site at this time.

\section{Discussion}

In this study, we tested whether MSCs isolated from bone marrow of EGFP transgenic mice and delivered intranasally would enter the OB, survive, and migrate over time to a distal lesion site in the striatum. We found no evidence of viable MSC-EGFPs in any region of the brain at 3 hours, 1 or 7 days, or 2 months after intranasal administration. The lack of MSC-EGFPs was not due to an intrinsic inability of the cells to engraft or survive in vivo, because MSC-EGFPs implanted directly in the striatum survived for at least 7 days. Notably, in our search for viable MSC-EGFPs in brain, we observed high levels of autofluorescence in both the intact $\mathrm{OB}$ and in the lesioned striatum several weeks after a mechanical lesion. We think it is conceivable that this autofluorescence could 


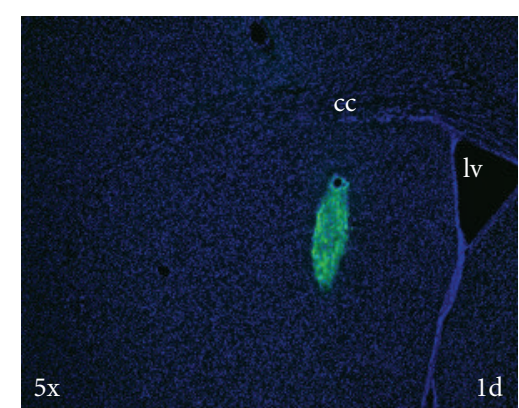

(a)

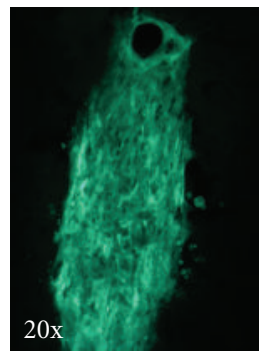

(c)

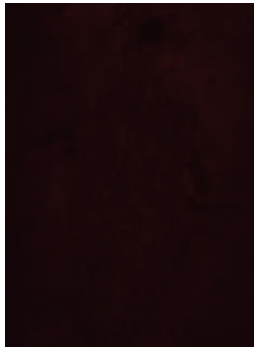

$\left(c^{\prime}\right)$

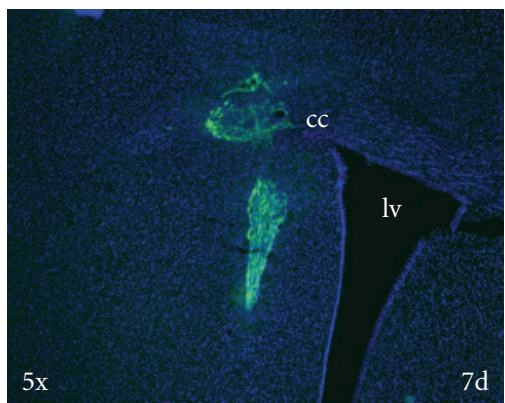

(e)

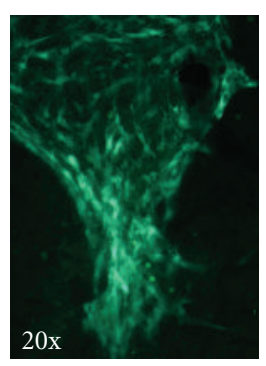

(g)

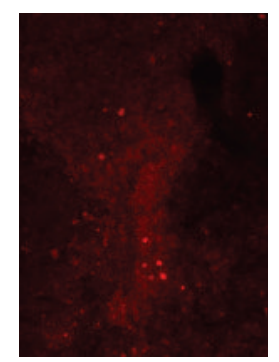

$\left(\mathrm{g}^{\prime}\right)$

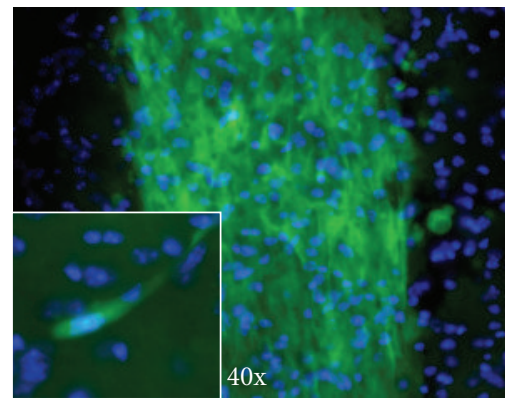

(b)

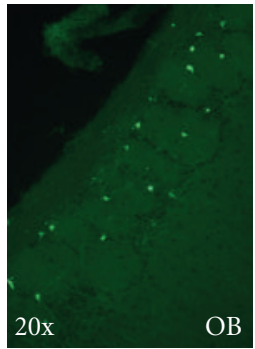

(d)

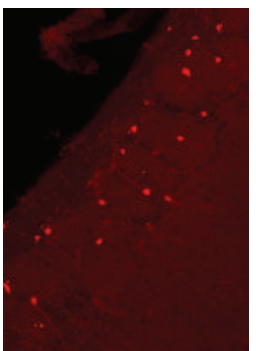

$\left(d^{\prime}\right)$

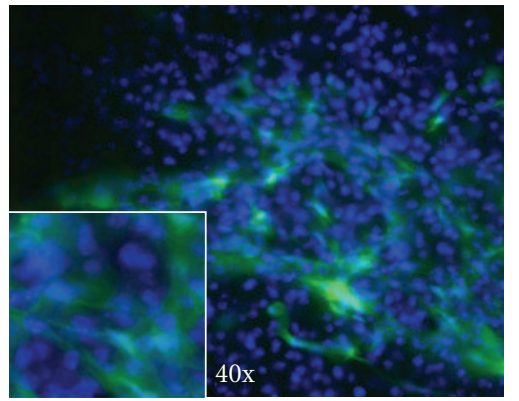

(f)

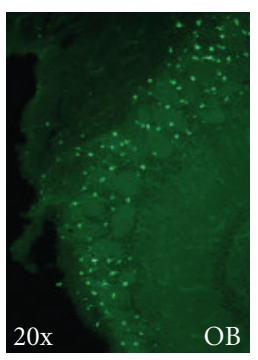

(h)

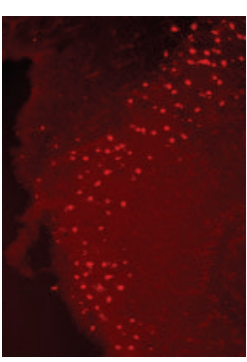

$\left(\mathrm{h}^{\prime}\right)$

Figure 6: Detection of MSC-EGFPs after intrastriatal delivery. (a) 1d after implantation, endogenous eGFP fluorescence from MSCs is found proximal to the injector needle track. Tissue counterstained with DAPI. (b) At higher magnification (40x), fibroblast-like structure of implanted MSC-EGFPs can be seen. Fluorescence is detected on GFP (c), but not Texas Red ( $c^{\prime}$ ) emission filters. In the OB, autofluorescence is detected on both the GFP (d) and Texas Red ( $\mathrm{d}^{\prime}$ ) emission filters. (e) 7d after implantation, endogenous eGFP fluorescence from MSCs is found around the injector needle track. Tissue counterstained with DAPI. (f) At higher magnification (40x), implanted MSC-EGFPs can be seen. Fluorescence is detected on GFP $(\mathrm{g})$, and Texas Red $\left(\mathrm{g}^{\prime}\right)$ emission filters, although there is no overlap with GFP signal. In the OB, autofluorescence is detected on both the GFP $(\mathrm{h})$ and Texas Red $\left(\mathrm{h}^{\prime}\right)$ emission filters. Abbreviations: cc: corpus callosum; lv: lateral ventricle.

be mistaken for the presence of EGFP-labeled MSCs. This is consistent with past studies demonstrating the difficulty in discriminating between true GFP signal and artifact, which occurs, at least in part, because autofluorescence emission spectra partially overlap the emission of GFP $[28,29,33,35]$.

Recently, it has been reported that intranasal delivery of fluorescently labeled rat MSCs to mice resulted in migration of a remarkable number of cells to olfactory bulb, cortical, hippocampal, striatal, and thalamic brain structures within hours of cell administration [24-26]. There are several possible reasons for the apparent discrepancy with our study. First, we administered 6-fold fewer cells than Danielyan et al., raising the possibility that the number of starting MSCEGFPs was not sufficient to yield significant and detectable 
numbers of MSCs in the brain. However, this seems unlikely given that between 500-2000 MSCs were detectable in the OB within the first $4 \mathrm{hr}$ after intranasal administration in the Danielyan studies [24, 26], and a 6-fold decrease in this number of OB MSCs would still be detectable with the methods described here. Second, the use of GFP in our study could have reduced the capacity of the MSCs for survival. However, it has recently been shown that the presence of GFP in MSCs does not adversely effect the survival of stem cells in the brain [11]. Third, it is possible that the mechanical striatal lesion triggered a tissue response that led to rejection of the MSCs. Mechanical lesions are known to induce an inflammatory response, and we found that more than 2 months after intrastriatal ascorbic acid administration, there was still robust GFAP expression around the injector needle track. Although we do not characterize what produces this immune response, it is likely that the chemical milieu around the damaged tissue includes cytokines, growth factors, and other potential chemical signals that could attract-or repel-the MSC-EGFPs. This is consistent with prior work showing that the inflammatory response to intrastriatal MSC delivery itself is sufficient to reject the engrafted MSCs over time $[10,36]$. However, Coyne et al. show that MSCs survive for at least a week before rejection whereas we never saw evidence of surviving MSCs after intranasal delivery. We believe the most likely explanation is that the MSC-EGFPs simply fail to pass through the olfactory mucosa and epithelium, and are thus never exposed to the brain itself.

Although we detected no MSCs in the brain after intranasal delivery, there was abundant fluorescence. True fluorescence signal from GFP has a narrower emission spectrum than autofluorescence. Thus, true GFP emissions will not be detected with longer wavelength $(>550 \mathrm{~nm})$ bandpass filters (i.e., Texas Red). In our studies, a GFP-specific signal was present in MSC-EGFPs in culture and in the striatum of mice that received intrastriatal infusions of cells, since fluorescent signal was detected only under the green (GFP bandpass) and not under the red (Texas Red) emission filters. However, in mice administered MSC-EGFPs intranasally, no GFP-specific signal could be discriminated from autofluorescence. Every structure that was fluorescent under the GFP bandpass filter was detected with equal intensity under the Texas Red filter. These types of negative controls are often not reported in the literature, despite several papers calling for appropriate controls [28, 29, 35, 37].

The autofluorescence observed in the striatum in our study is strongly associated with the mechanical lesion site and GFAP expression and is most likely due to damaged tissue products and lipofuscin, which autofluoresces at wavelengths similar to GFP [35]. In the OB, autofluorescent structures were observed in tissue from mice that received intranasal saline or MSC-EGFPs, and also from mice that did not receive any intranasal treatment, suggesting that physical stress caused by intranasal injections is not the cause of $\mathrm{OB}$ autoflourescence. Little is known about autofluorescence in the $\mathrm{OB}$, but two reports describe naturally occurring lipofuscin in the $\mathrm{OB}$ and its relationship to oxidative enzymatic activity [38, 39].
In an attempt to circumvent autofluorescence, we performed electron microscopy on tissue processed for GFP immunoreactivity using DAB as the chromagen. It has previously been shown at the ultrastructural level that GFP is found in clusters associated with endoplasmic reticulum [40-42]. In our study, we did not observe GFP-specific staining at the ultrastructural level in tissue taken from the striatum of mice 7 days or 2 months after intranasal delivery of MSC-EGFPs. Rather, in regions that stained positively for DAB (see Figure 5(a)), we observed many examples of cells in various stages of degradation, including shrunken, electrondense necrotic neurons with pyknotic nuclei. This type of morphology has been described previously [34], and together with the high levels of GFAP found around the striatal injection site, is consistent with the likelihood that the striatal lesion resulted in an inflammatory response that triggered cellular degradation and necrosis, resulting in deposits of autofluorescent debris (e.g., lipofuscin). Interestingly, similar structures were not observed in the OB (data not shown).

The phenotype of MSCs may play a critical role in viability after implantation. FACS-based phenotyping is commonly used to identify MSC isolated from bone marrow, but profiles and marker selection vary among studies. Thus, MSCs have been shown to be positive for a range of antigens including CD44, CD105 (SH2; endoglin), CD106 (VCAM1), CD166, CD29, CD73 (SH3 and SH4), CD90 (Thy-1), CD117, STRO-1, and Sca-1 while lacking expression of hematopoietic and endothelial surface molecules, such as CD11b, CD14, CD31, CD33, CD34, CD133, and CD45 (reviewed in [43]). In the current study, FCM phenotyping of the MSC-EGFPs at passage 4 in mitogen-containing culture conditions revealed strong expression of Sca-1, CD29, and CD44 and no expression of CD106, CD105, CD73, CD45, and CD11b. To gain further insight into their phenotypic properties, we compared the MSC-EGFP profile with that from bone marrow cells (BMCs) cultured using an established protocol [30]. In our hands, BMCs cultured for three weeks in serum-containing mitogen-free media segregated into two cell populations with different expression profiles. A fraction of large cells that were morphologically similar to MSC-EGFPs and expressed Sca-1 (weak expression), CD29, and CD44; a fraction of small cells that were negative for all markers analyzed. These data demonstrate that-despite being derived by established methods - the clonally expanded MSC-EGFPs used in this study had a BMC-derived phenotype that resembled some characteristics of MSCs but were clearly not of hematopoietic or fibroblast lineages $[6,24,30]$. It should be noted that this line of MSC-EGFPs was used previously in an in vitro differentiation paradigm to derive neural cell populations [27]. Together, these finding underscore the importance of establishing consistent standards for defining MSCs and MSC subtypes.

\section{Conclusions}

In summary, we found no evidence that intranasally delivered MSC-EGFPs migrated into, or persisted in, the brains of mice with striatal lesions whereas intrastriatally implanted 
stem cells survived for at least $7 \mathrm{~d}$. Additionally, we observed a high degree of autofluorescence in the intact $\mathrm{OB}$ and the lesioned striatum that could easily be mistaken for the presence of EGFP-labeled MSCs. These last observations confirm past studies demonstrating that many standard techniques used for tracking GFP fluorescence can produce misleading artifacts [28, 29] unless appropriate controls are included and disclosed [28, 29, 35, 37].

\section{Disclosure}

B. M. Cohen is a coinventor on a patent application: Cataldo et al., "Methods and Compositions for the Treatment of Medical Disorders," that describes the use of MSCs to deliver growth or neurogenerative factors. None of the other authors report any biomedical financial interests or potential conflicts of interest.

\section{Funding}

Center Grant, Stanley Medical Research Institute, and Frazier Research Institute (to B. M. Cohen) funded this paper.

\section{Acknowledgments}

The authors are immensely grateful to A. M. Cataldo, whose passion and intellect were the driving force behind this and other MSC studies. Tragically, she passed away before this work could be completed and the knowledge gained used for future advances.

\section{References}

[1] J. E. Grove, E. Bruscia, and D. S. Krause, "Plasticity of bone marrow-derived stem cells," Stem Cells, vol. 22, no. 4, pp. 487500, 2004.

[2] M. F. Pittenger, A. M. Mackay, S. C. Beck et al., "Multilineage potential of adult human mesenchymal stem cells," Science, vol. 284, no. 5411, pp. 143-147, 1999.

[3] T. R. Brazelton, F. M. V. Rossi, G. I. Keshet, and H. M. Blau, "From marrow to brain: expression of neuronal phenotypes in adult mice," Science, vol. 290, no. 5497, pp. 1775-1779, 2000.

[4] Y. Jiang, B. N. Jahagirdar, R. L. Reinhardt et al., "Pluripotency of mesenchymal stem cells derived from adult marrow," $\mathrm{Na}$ ture, vol. 418, no. 6893, pp. 41-49, 2002.

[5] E. Mezey, K. J. Chandross, G. Harta, R. A. Maki, and S. R. McKercher, "Turning blood into brain: cells bearing neuronal antigens generated in vivo from bone marrow," Science, vol. 290, no. 5497, pp. 1779-1782, 2000.

[6] D. Woodbury, E. J. Schwarz, D. J. Prockop, and I. B. Black, "Adult rat and human bone marrow stromal cells differentiate into neurons," Journal of Neuroscience Research, vol. 61, no. 4, pp. 364-370, 2000.

[7] E. Check, "Stem-cell paper corrected," Nature, vol. 447, no. 7146, p. 763, 2007.

[8] B. Neuhuber, G. Gallo, L. Howard, L. Kostura, A. Mackay, and I. Fischer, "Reevaluation of in vitro differentiation protocols for bone marrow stromal cells: disruption of actin cytoskeleton induces rapid morphological changes and mimics neuronal phenotype," Journal of Neuroscience Research, vol. 77, no. 2, pp. 192-204, 2004.
[9] S. A. Azizi, D. Stokes, B. J. Augelli, C. DiGirolamo, and D. J. Prockop, "Engraftment and migration of human bone marrow stromal cells implanted in the brains of albino rats- similarities to astrocyte grafts," Proceedings of the National Academy of Sciences of the United States of America, vol. 95, no. 7, pp. 3908-3913, 1998.

[10] T. M. Coyne, A. J. Marcus, K. Reynolds, I. B. Black, and D. Woodbury, "Disparate host response and donor survival after the transplantation of mesenchymal or neuroectodermal cells to the intact rodent brain," Transplantation, vol. 84, no. 11, pp. 1507-1516, 2007.

[11] T. C. Moloney, P. Dockery, A. J. Windebank, F. P. Barry, L. Howard, and E. Dowd, "Survival and immunogenicity of mesenchymal stem cells from the green fluorescent protein transgenic rat in the adult rat brain," Neurorehabilitation and Neural Repair, vol. 24, no. 7, pp. 645-656, 2010.

[12] N. Terada, T. Hamazaki, M. Oka et al., "Bone marrow cells adopt the phenotype of other cells by spontaneous cell fusion," Nature, vol. 416, no. 6880, pp. 542-545, 2002.

[13] Q. L. Ying, J. Nichols, E. P. Evans, and A. G. Smith, "Changing potency by spontaneous fusion,” Nature, vol. 416, no. 6880, pp. 545-548, 2002.

[14] K. Kurozumi, K. Nakamura, T. Tamiya et al., "Mesenchymal stem cells that produce neurotrophic factors reduce ischemic damage in the rat middle cerebral artery occlusion model," Molecular Therapy, vol. 11, no. 1, pp. 96-104, 2005.

[15] Y. S. Levy, M. Bahat-Stroomza, R. Barzilay et al., "Regenerative effect of neural-induced human mesenchymal stromal cells in rat models of Parkinson's disease," Cytotherapy, vol. 10, no. 4, pp. 340-352, 2008.

[16] N. K. Venkataramana, S. K. V. Kumar, S. Balaraju et al., "Openlabeled study of unilateral autologous bone-marrow-derived mesenchymal stem cell transplantation in Parkinson's disease," Translational Research, vol. 155, no. 2, pp. 62-70, 2010.

[17] B. J. Balin, R. D. Broadwell, M. Salcman, and M. El-Kalliny, "Avenues for entry of peripherally administered protein to the central nervous system in mouse, rat, and squirrel monkey," The Journal of Comparative Neurology, vol. 251, no. 2, pp. 260280, 1986.

[18] L. Illum, "Transport of drugs from the nasal cavity to the central nervous system," European Journal of Pharmaceutical Sciences, vol. 11, no. 1, pp. 1-18, 2000.

[19] X. F. Liu, J. R. Fawcett, R. G. Thorne, T. A. DeFor, and W. H. Frey, "Intranasal administration of insulin-like growth factorI bypasses the blood-brain barrier and protects against focal cerebral ischemic damage," Journal of the Neurological Sciences, vol. 187, no. 1-2, pp. 91-97, 2001.

[20] S. Mathison, R. Nagilla, and U. B. Kompella, "Nasal route for direct delivery of solutes to the central nervous system: fact or fiction?" Journal of Drug Targeting, vol. 5, no. 6, pp. 415-441, 1998.

[21] R. G. Thorne, G. J. Pronk, V. Padmanabhan, and W. H. Frey, "Delivery of insulin-like growth factor-I to the rat brain and spinal cord along olfactory and trigeminal pathways following intranasal administration," Neuroscience, vol. 127, no. 2, pp. 481-496, 2004.

[22] F. Lemiale, W. P. Kong, L. M. Akyürek et al., "Enhanced mucosal immunoglobulin A response of intranasal adenoviral vector human immunodeficiency virus vaccine and localization in the central nervous system," Journal of Virology, vol. 77, no. 18, pp. 10078-10087, 2003.

[23] D. Damjanovic, X. Zhang, J. Mu, M. Fe Medina, and Z. Xing, "Organ distribution of transgene expression following 
intranasal mucosal delivery of recombinant replication-defective adenovirus gene transfer vector," Genetic Vaccines and Therapy, vol. 6, article no. 5, 2008.

[24] L. Danielyan, R. Schäfer, A. von Ameln-Mayerhofer et al., "Intranasal delivery of cells to the brain," European Journal of Cell Biology, vol. 88, no. 6, pp. 315-324, 2009.

[25] C. T. J. van Velthoven, A. Kavelaars, F. van Bel, and C. J. Heijnen, "Nasal administration of stem cells: a promising novel route to treat neonatal ischemic brain damage," Pediatric Research, vol. 68, no. 5, pp. 419-422, 2010.

[26] L. Danielyan, R. Schäfer, A. Von Ameln-Mayerhofer et al., "Therapeutic efficacy of intranasally delivered mesenchymal stem cells in a rat model of parkinson disease," Rejuvenation Research, vol. 14, no. 1, pp. 3-16, 2011.

[27] C. W. D. Chen, R. M. Boiteau, W. F. T. Lai, S. W. Barger, and A. M. Cataldo, "sAPP $\alpha$ enhances the transdifferentiation of adult bone marrow progenitor cells to neuronal phenotypes," Current Alzheimer Research, vol. 3, no. 1, pp. 63-70, 2006.

[28] T. R. Brazelton and H. M. Blau, "Optimizing techniques for tracking transplanted stem cells in vivo," Stem Cells, vol. 23, no. 9, pp. 1251-1265, 2005.

[29] K. A. Jackson, D. S. Snyder, and M. A. Goodell, "Skeletal muscle fiber-specific green autofluorescence: potential for stem cell engraftment artifacts," Stem Cells, vol. 22, no. 2, pp. 180-187, 2004.

[30] M. Soleimani and S. Nadri, "A protocol for isolation and culture of mesenchymal stem cells from mouse bone marrow," Nature Protocols, vol. 4, no. 1, pp. 102-106, 2009.

[31] H. Sauer and W. H. Oertel, "Progressive degeneration of nigrostriatal dopamine neurons following intrastriatal terminal lesions with 6-hydroxydopamine: a combined retrograde tracing and immunocytochemical study in the rat," Neuroscience, vol. 59, no. 2, pp. 401-415, 1994.

[32] G. Paxinos and K. B. J. Franklin, The Mouse Brain in Stereotaxic Coordinates, Academic Press, San Diego, Calif, USA, 2001.

[33] S. A. Schnell, W. A. Staines, and M. W. Wessendorf, "Reduction of lipofuscin-like autofluorescence in fluorescently labeled tissue," Journal of Histochemistry \& Cytochemistry, vol. 47, no. 6, pp. 719-730, 1999.

[34] D. G. Fujikawa, S. Zhao, X. Ke, S. S. Shinmei, and S. G. Allen, "Mild as well as severe insults produce necrotic, not apoptotic, cells: evidence from 60-min seizures," Neuroscience Letters, vol. 469, no. 3, pp. 333-337, 2010.

[35] N. Billinton and A. W. Knight, "Seeing the wood through the trees: a review of techniques for distinguishing green fluorescent protein from endogenous autofluorescence," Analytical Biochemistry, vol. 291, no. 2, pp. 175-197, 2001.

[36] T. M. Coyne, A. J. Marcus, D. Woodbury, and I. B. Black, "Marrow stromal cells transplanted to the adult brain are rejected by an inflammatory response and transfer donor labels to host neurons and glia," Stem Cells, vol. 24, no. 11, pp. 24832492, 2006.

[37] Y. Long and K. Y. Yang, "Bone marrow derived cells for brain repair: recent findings and current controversies," Current Molecular Medicine, vol. 3, no. 8, pp. 719-725, 2003.

[38] E. P. Gilissen, R. E. Jacobs, E. R. Mcguinness, and J. M. Allman, "Topographical localization of lipofuscin pigment in the brain of the aged fat-tailed dwarf lemur (Cheirogaleus medius) and grey lesser mouse lemur (Microcebus murinus): comparison to iron localization," American Journal of Primatology, vol. 49, no. 2, pp. 183-193, 1999.

[39] R. A. Vaishnav, M. L. Getchell, L. Huang, M. A. Hersh, A. J. Stromberg, and T. V. Getchell, "Cellular and molecular characterization of oxidative stress in olfactory epithelium of harl- equin mutant mouse," Journal of Neuroscience Research, vol. 86, no. 1, pp. 165-182, 2008.

[40] A. R. Muotri, K. Nakashima, N. Toni, V. M. Sandler, and F. H. Gage, "Development of functional human embryonic stem cell-derived neurons in mouse brain," Proceedings of the National Academy of Sciences of the United States of America, vol. 102, no. 51, pp. 18644-18648, 2005.

[41] J. Priller, D. A. Persons, F. F. Klett, G. Kempermann, G. W. Kreutzberg, and U. Dirnagl, "Neogenesis of cerebellar Purkinje neurons from gene-marked bone marrow cells in vivo," Journal of Cell Biology, vol. 155, no. 5, pp. 733-738, 2001.

[42] M. Wernig, F. Benninger, T. Schmandt et al., "Functional integration of embryonic stem cell-derived neurons in vivo," Journal of Neuroscience, vol. 24, no. 22, pp. 5258-5268, 2004.

[43] S. Bobis, D. Jarocha, and M. Majka, "Mesenchymal stem cells: characteristics and clinical applications," Folia Histochemica et Cytobiologica, vol. 44, no. 4, pp. 215-230, 2006. 

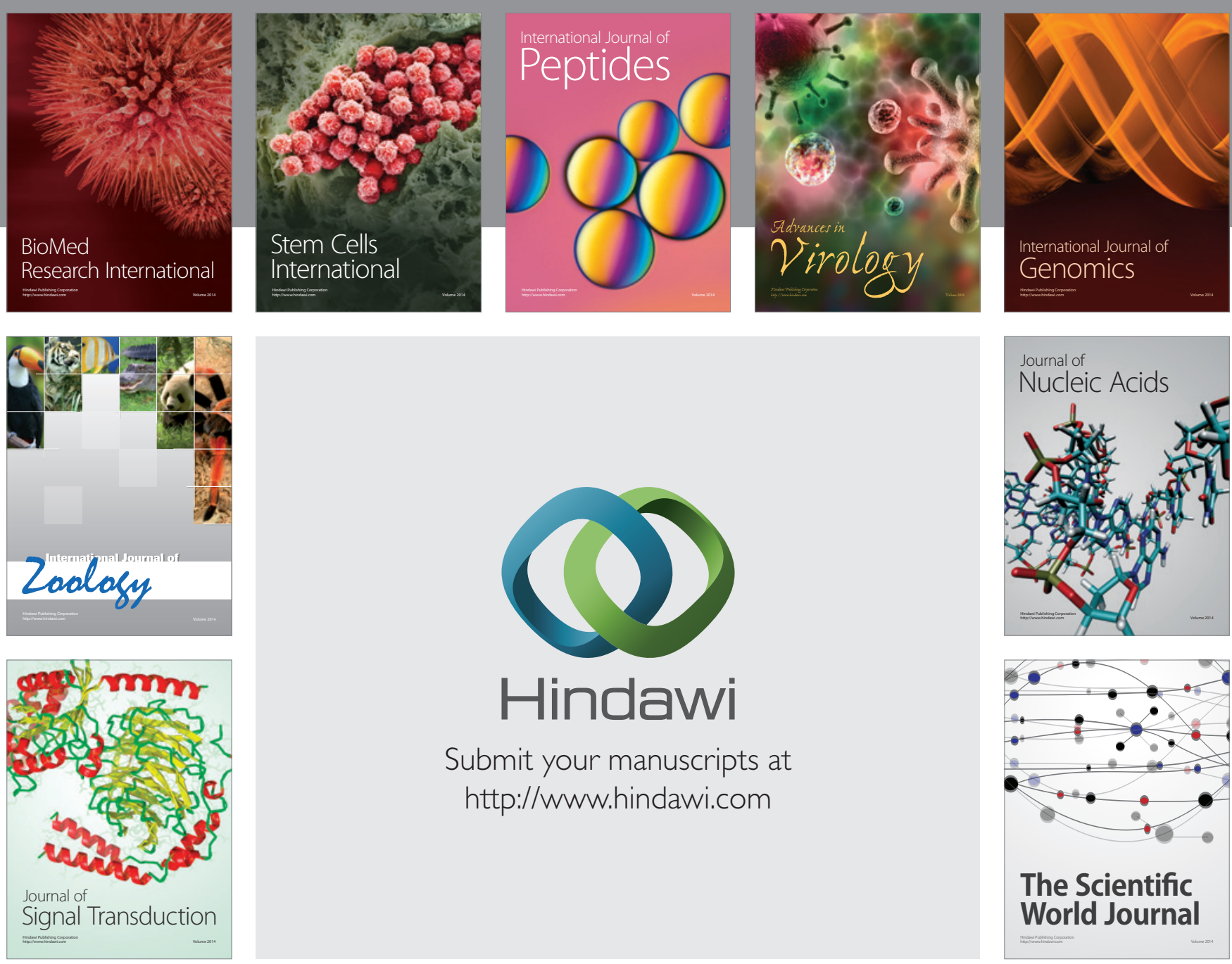

Submit your manuscripts at

http://www.hindawi.com
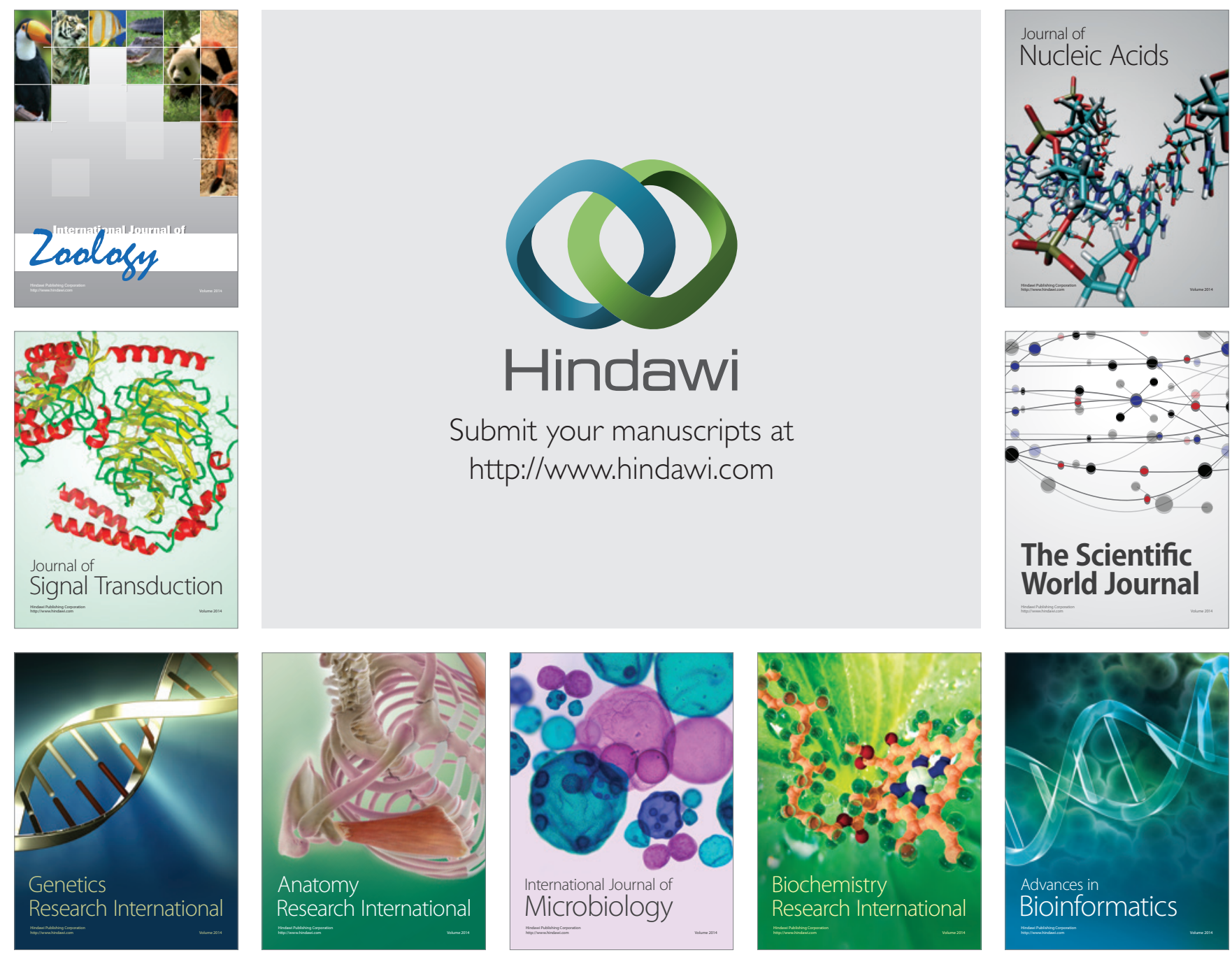

The Scientific World Journal
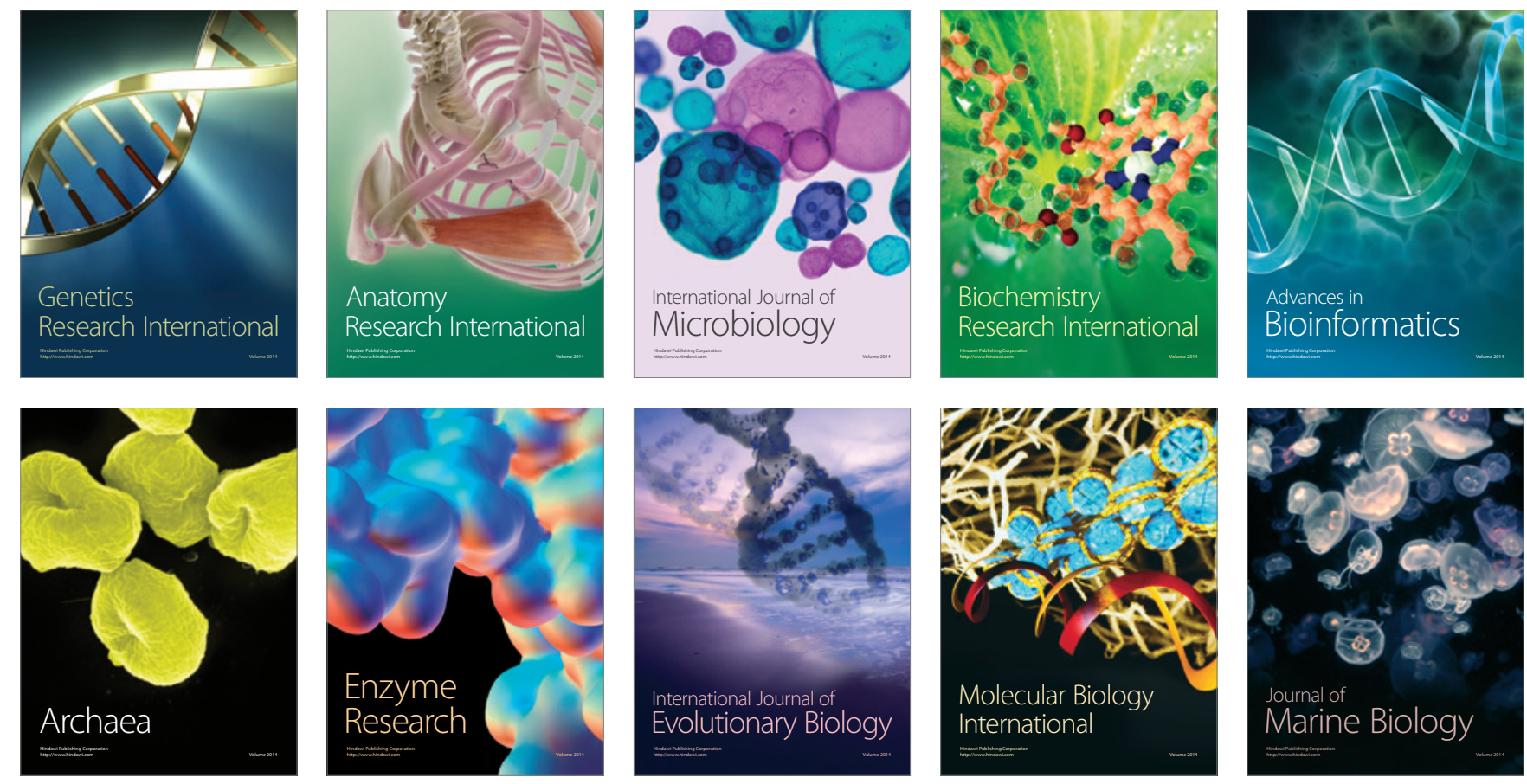